\title{
Incidental colorectal computed tomography abnormalities: Would you send every patient for a colonoscopy?
}

\author{
Edy Stermer $M D^{1}$, Alexandra Lavy $M D^{1}$, Tova Rainis $M D^{1}$, Omer Goldstein $M D^{1}$,
} Dean Keren $M D^{1}$, Abdel-Rauf Zeina $M^{2}$

\begin{abstract}
E Stermer, A Lavy, T Rainis, O Goldstein, D Keren, A-R Zeina. Incidental colorectal computed tomography abnormalities: Would you send every patient for a colonoscopy? Can J Gastroenterol 2008;22(9):758-760.
\end{abstract}

BACKGROUND: The clinical significance of colorectal wall thickening (CRWT) in patients undergoing abdominal computed tomography (CT) has not yet been definitively established.

OBJECTIVES: To compare alleged findings on abdominal CT with those of a follow-up colonoscopy.

METHODS: Ninety-four consecutive patients found to have largebowel abnormalities on abdominal CT were referred for colonoscopy. Of these patients, 48 were referred for a suspected colorectal tumour and 46 for CRWT. Colonoscopy was performed and findings were compared.

RESULTS: Of the 48 suspected colorectal tumours, 34 were determined to be neoplastic lesions on colonoscopy. Of these, 26 were malignant and eight were benign. Colonoscopy revealed no abnormality in 30 of 46 patients with CRWT as a solitary finding, and revealed some abnormality in 16 patients (12 had diverticular disease, four had benign neoplastic lesions).

CONCLUSIONS: CRWT as an incidental and solitary finding on CT should not be regarded as a pathology prompting a colonoscopy. Approximately two-thirds of the patients had a normal colonoscopy and the remaining patients had benign lesions ( $12 \mathrm{had}$ diverticular disease and four had benign neoplastic lesions). However, many of these patients seem to warrant colonoscopy regardless of CT findings, particularly patients who have a family history of colorectal cancer, have positive fecal occult blood test results or who are older than 50 years of age.

Key Words: Colonoscopy; Colorectal cancer; Colorectal wall thickening; CT; Incidental finding

\section{Des anomalies imprévues à la tomodensitométrie colorectale : Enverriez-vous tous les patients subir une coloscopie?}

\begin{abstract}
HISTORIQUE : La signification clinique de l'épaisseur de la paroi colorectale (ÉPCR) chez les patients qui subissent une tomodensitométrie (TD) abdominale n'est pas complètement établie.

OBJECTIFS : Comparer les observations présumées de la TD abdominale à celles d'une coloscopie de suivi.

MÉTHODOLOGIE : Quatre-vingt-quatorze patients consécutifs chez qui on a observé des anomalies du gros intestin à la TD abdominale ont été aiguillés vers la coloscopie. De ce nombre, 48 l'ont été en raison d'une présomption de tumeur colorectale et 46 , en raison d'une présomption d'ÉPCR. Une fois la coloscopie effectuée, les auteurs ont comparé les résultats.

RÉSULTATS : Sur les 48 présomptions de tumeur colorectale, on a déterminé que 34 étaient des lésions néoplasiques. De ce nombre, 26 étaient malignes et huit, bénignes. La coloscopie n’a révélé aucune anomalie chez 30 des 46 patients pour qui l'ÉPCR était la seule observation, et certaines anomalies chez 16 patients (12 avaient une diverticulite et quatre, des lésions néoplasiques bénignes).

CONCLUSIONS : Une ÉPCR qui représente une observation imprévue et unique à la TD ne devrait pas être perçue comme une pathologie justifiant une coloscopie. Environ les deux tiers des patients avaient une coloscopie normale et les autres, des lésions bénignes (12 avaient une diverticulite et quatre, une lésion néoplasique bénigne). Cependant, bon nombre de ces patients semblent avoir besoin d'une coloscopie indépendamment des résultats de la TD, notamment ceux qui ont des antécédents familiaux de cancer colorectal, dont les résultats de la recherche de sang occulte dans les selles sont positifs ou qui ont plus de 50 ans.
\end{abstract}

$\mathrm{C}$ olorectal wall thickening (CRWT) is not a rare finding on computed tomography (CT) scans of the abdomen. Although the clinical significance of this finding is being disputed, it has been reported to reflect mainly inflammatory bowel disease, bowel ischemia or colorectal carcinoma $(1,2)$. However, it may also represent an incidental finding or an artifact without clinical significance (3). The aim of the present study was to establish the value of colonoscopy in confirming incidental CT findings of the colon and, particularly, those of CRWT.

\section{METHODS}

The charts of 126 consecutive patients who underwent colonoscopy due to colorectal abnormalities detected on CT examinations of the abdomen between January 1, 2006, and December 31, 2007, were reviewed. Indications for CT examinations of the abdomen were family history of colorectal cancer, abdominal pain, postive fecal occult blood test (FOBT) results, anemia, weight loss, constipation, recurrent largebowel obstruction and nonrelated gastrointestinal tract reasons. The patients were selected using the computerized

${ }^{1}$ Gastroenterology Service; ${ }^{2}$ Department of Radiology, Bnai Zion Medical Center, Bruce Rappaport Faculty of Medicine, Technion-Israel Institute of Technology, Haifa, Israel

Correspondence: Dr Edy Stermer, Department of Gastroenterology, Bnai Zion Medical Center, 47 Golomb Street, PO Box 4940, Haifa 31048,

Israel. Telephone 9-724-835-9426, fax 9-724-835-9726, e-mail edystermer@yahoo.com

Received for publication March 22, 2008. Accepted May 28, 2008 

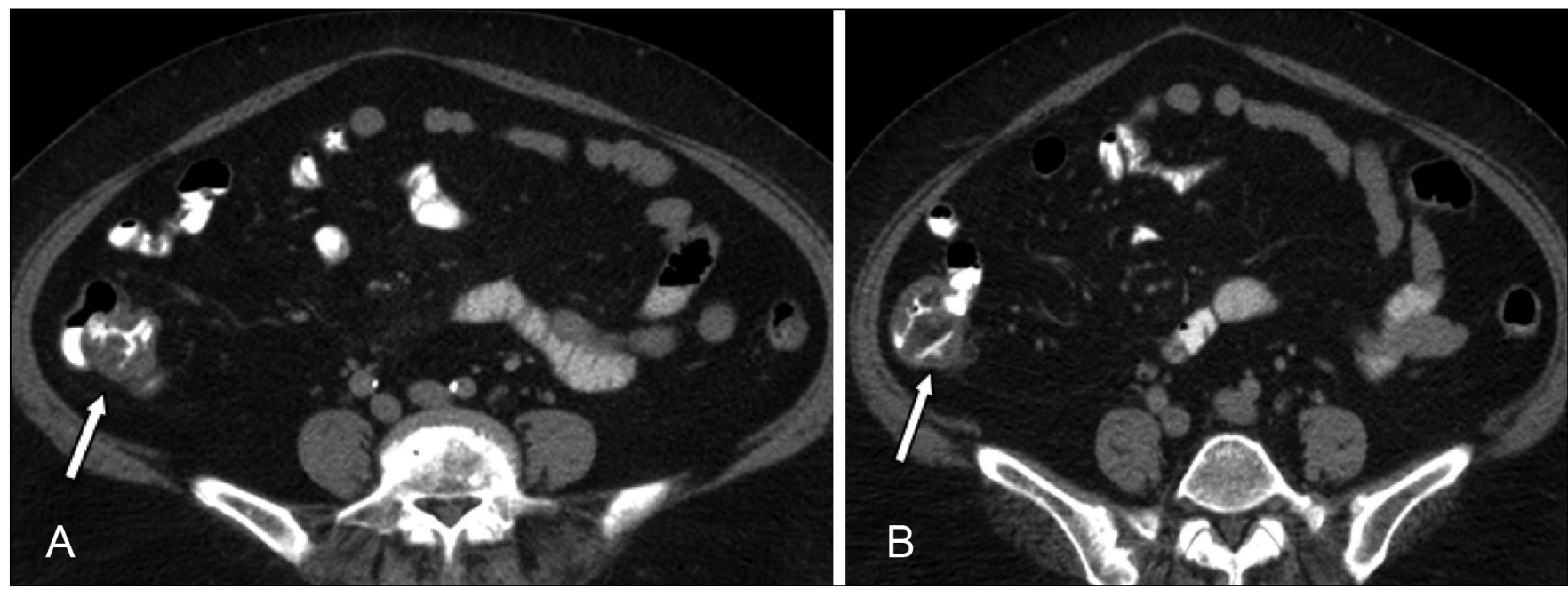

Figure 1) Computed tomography (CT) images of the abdomen in a 72-year-old woman with anemia and abdominal pain. The CT scan was performed using a 64-row multidetector CT scanner (VCT; General Electric Medical Systems, USA). A, B Axial CT images obtained at the level of the cecum show cecal wall thickening associated with luminal narrowing (arrows). The pericolic fat appears to be normal. Colonoscopy showed no abnormality

International Classification of Diseases, Ninth Edition under the diagnosis 'abnormal radiological findings'. In the Bnai Zion Medical Center's (Haifa, Israel) open-access system, these 126 patients represented approximately $1 \%$ of the total number of patients who underwent colonoscopy during the same period.

The standard preparation for colonoscopy was based on the ingestion of two bottles of Soffodex (Dexxon Ltd, Israel) and clear liquids $24 \mathrm{~h}$ before the examination. Colonoscopy was performed using an Olympus colonoscope (GIF Q165; Olympus America Inc, USA), and patients received conscious sedation with fentanyl (Beatryl; Abic, Israel). Experienced endoscopists performed the colonoscopies, and biopsies were obtained as needed. Patients were included if bowel preparation was satisfactory and if they were older than 18 years of age.

CT examinations were performed according to the following protocol. Scanning was performed using a 64-row multidetector CT scanner (VCT; General Electric Medical Systems, USA). Patients were studied in the supine position after ingestion of $800 \mathrm{~mL}$ to $1200 \mathrm{~mL}$ of oral contrast material at least $1 \mathrm{~h}$ before scanning. A bolus of $60 \mathrm{~mL}$ to $80 \mathrm{~mL}$ of iomeprol contrast medium was injected intravenously with a mechanical power injector. Three millimetres has been considered to be the upper limit of normal for colonic wall thickness (4). As a result, any part of the large bowel with a wall thickness greater than $3 \mathrm{~mm}$ was considered abnormal. All CT examinations of the abdomen were reviewed by an expert radiologist. Correlation was sought between the alleged findings on CT and the corresponding diagnosis on colonoscopy. Approval from the institutional review board was not required because the present study was retrospective and observational.

\section{RESULTS}

Thirty-two patients were excluded from the study due to inadequate preparation $(n=14)$, incomplete examination $(n=6)$, previous colonic resection $(n=6)$, incomplete data regarding colonoscopy results $(n=4)$ and age older than 85 years $(n=2)$. The final cohort included 94 patients (38 men and 56 women; mean $[ \pm \mathrm{SD}]$ age $66 \pm 7$ years).
Of these 94 patients, 48 were referred for colonoscopy because of suspicion of a neoplastic lesion and because they were determined to have more than one of the following colorectal abnormalities on CT: large-bowel wall thickness greater than $3 \mathrm{~mm}$ (circumferential or partial), intraluminal soft-tissue filling defect, intestinal obstruction (partial), pericolic fat attenuation or enlarged pericolic lymph nodes. Of the 48 patients with suspected colorectal tumours on abdominal CT, $34(71 \%)$ were determined to have neoplastic lesions on colonoscopy. Of these, 26 were malignant and eight were benign. In the remaining 14 patients, colonoscopy revealed no abnormality.

In 46 patients with CRWT as a solitary CT finding, colonoscopy revealed no abnormality in 30 patients $(65 \%)$ and some pathology in $16(35 \%)$. Of these 16 patients, 12 had diverticular disease and four had benign neoplastic lesions. The distribution of cases of CRWT according to the area of the large bowel was as follows: cecum $(n=8)$, ascending colon $(n=13)$, transverse colon $(n=4)$, descending colon $(n=3)$, sigmoid colon $(n=12)$ and rectum $(n=6)$. Figure 1 shows CT images that demonstrate cecal wall thickening. Of the 12 cases in which diverticular disease was found at colonoscopy, only eight correlated with the area of the colon showing CRWT by CT, while the others were simply incidental colonoscopy findings. In two of the four cases in which a benign neoplastic lesion was found at colonoscopy, the area of the finding (rectosigmoid) correlated in both examinations.

\section{DISCUSSION}

Large-bowel wall thickening or soft-tissue filling defects may be reported as incidental findings in patients undergoing abdominal CT examinations. Patients might consequently be referred for unnecessary colonoscopy. The clinical significance of CRWT in this population has not yet been definitively established. Moreover, such findings are not considered to be indications for colonoscopy by the American Society for Gastrointestinal Endoscopy. In the present study, the relationship between abdominal CT and colonoscopic findings was studied. The prevalence of neoplastic lesions (either malignant or benign) was $71 \%$ in the group of patients with suspected 
colorectal cancer on abdominal CT examinations. Patients in this group were referred for CT of the abdomen because of family history of colorectal cancer or other clinical indications. However, among patients with CRWT as an incidental finding on abdominal CT, only four of 46 patients (9\%) were found to have neoplastic lesions on colonoscopy; both lesions were benign.

The results of the present study contrast with those of Cai et al (5), whose study demonstrated a significant abnormality in $96 \%$ of patients with an incidental finding of thickening of the sigmoid and rectum; the yield of cecal wall thickening was much lower $(13 \%)$. In a prospective study by Rockey et al (6), which evaluated patients with wall thickening through the gastrointestinal tract, the authors found acute or chronic inflammation in 11 of 20 cases with colonic wall thickening, while adenocarcinoma was found in three cases, lymphoma in two cases, granulomatous disease in one case and cytomegalovirus infection in three cases. The examination found no abnormalities in only two patients.

Frequently, gastrointestinal wall thickening is evaluated visually by the radiologist on CT scans. A measurement of $2 \mathrm{~mm}$ to $3 \mathrm{~mm}$ has been used by some authors $(7,8)$ as the upper limit of normal thickness. Others $(9,10)$ have advocated any perceptible thickening to indicate disorders. However, potential pitfalls exist with this latter approach. It should be stressed that the normal thickness of the colonic wall varies greatly depending on the degree of distention. When the colon is distended, the wall should be less than $3 \mathrm{~mm}$ thick. Colonic wall thickening may be incorrectly reported as abnormal on

\section{REFERENCES}

1. Desai RK, Tagliabue JR, Wegryn SA, Einstein DM. CT evaluation of wall thickening in the alimentary tract. Radiographics 1991;11:771-83.

2. Choi D, Jin Lee S, Ah Cho Y, et al. Bowel thickening in patients with Crohn's disease: CT patterns and correlation with inflammatory activity. Clin Radiol 2003;58:68-74.

3. Padda M, Vadgama J, Sandhu P, Dev A, Giannikopoulus I. Clinical significance of incidental colorectal wall thickening on computed tomography scan in African-American and Hispanic patients. Dig Dis Sci 2007;52:3159-64.

4. Fisher JK. Normal colon wall thickness on CT. Radiology 1982;145:415-8.

5. Cai Q, Baumgarten DA, Affronti JP, Waring JP. Incidental findings of thickening luminal gastrointestinal organs on computed tomography: An absolute indication for endoscopy. Am J Gastroenterol 2003;98:1734-7.

6. Rockey DC, Halvorsen RA Jr, Higgins JL, Cello CP. Prospective evaluation of patients with bowel wall thickening.
CT if the bowel is collapsed or partially distended. Lack of distention of the large bowel when using oral contrast material may explain the discrepancy between CT and colonoscopic findings reported in the present study. Occasionally, due to fecal contents, fluid or colonic redundancy, the true thickness of the colonic wall is difficult to ascertain. We speculate that the differences among our results and those of other series might be the consequence of a lack of uniform criteria for the diagnosis of CRWT, which was also evident in the the results of the study by Moraitis et al (11). We suggest that patients with CT diagnosis of CRWT undergo colonoscopy, particularly in the presence of risk factors such as age (older than 50 years), positive FOBT or having a first-degree relative with colorectal cancer. Although the cohort of the present study included a relatively small number of cases, a study evaluating a larger number of patients might confirm these persuasive results.

\section{CONCLUSIONS}

According to our results, a solitary, incidental finding of a thickened large-bowel wall on CT examination has a poor correlation with endoscopic findings. Approximately two-thirds of the patients had a normal colonoscopy and the remaining patients had benign lesions. If colorectal disease is suspected on CT, careful attention to the technique is required for optimal evaluation. However, it should be stressed that many of these patients seem to warrant colonoscopy regardless of CT findings, particularly in patients who have a family history of colorectal cancer, have positive FOBT results or who are older than 50 years of age.

Am J Gastroenterol 1995;90:99-103.

7. Gore RM, Balthazar EJ, Ghahremani GG, Miller FH. CT features of ulcerative colitis and Crohn's disease. AJR Am J Roentgenol 1996;167:3-15.

8. James S, Balfe DM, Lee JK, Picus D. Small-bowel disease: Categorization by CT examination. AJR Am J Roentgenol 1987;148:863-8.

9. Scanlon MH, Blumberg ML, Ostrum BJ. Computed tomographic recognition of gastrointestinal pathology. Radiographics 1983;3:201-27.

10. Karahan OI, Dodd GD III, Chintapalli KN, Rhim H, Chopra S. Gastrointestinal wall thickening in patients with cirrhosis: Frequency and patterns at contrast-enhanced CT. Radiology 2000;215:103-7.

11. Moraitis D, Singh P, Jayadevan R, Cayten CD. Colonic wall thickening on computed tomography scan and clinical correlation. Does it suggest the presence of an underlying neoplasia? Am Surg 2006;72:269-71. 


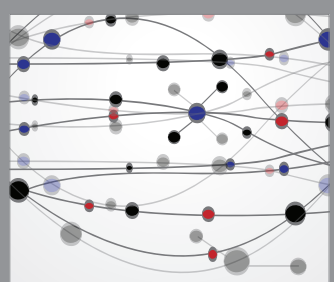

The Scientific World Journal
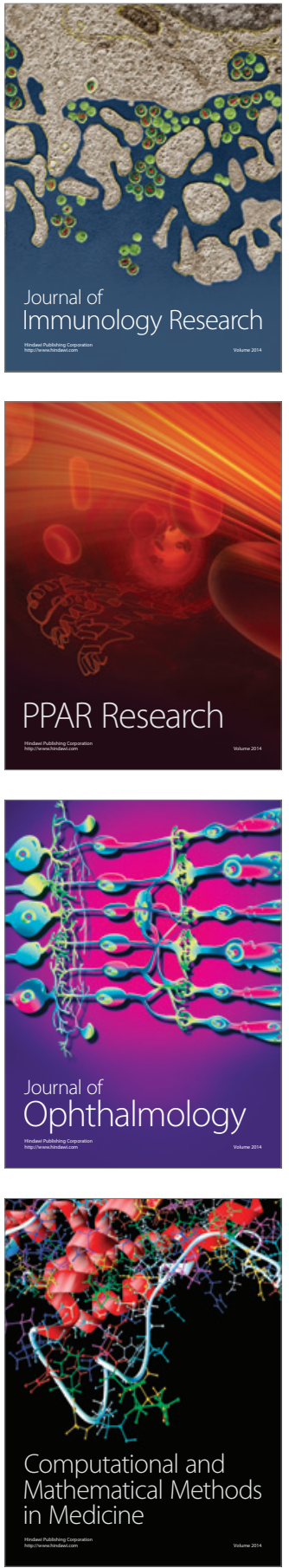

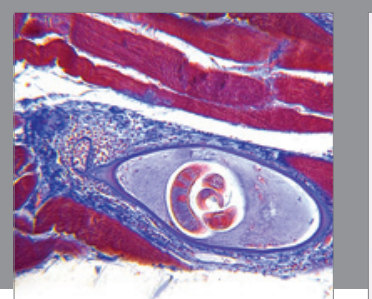

Gastroenterology Research and Practice

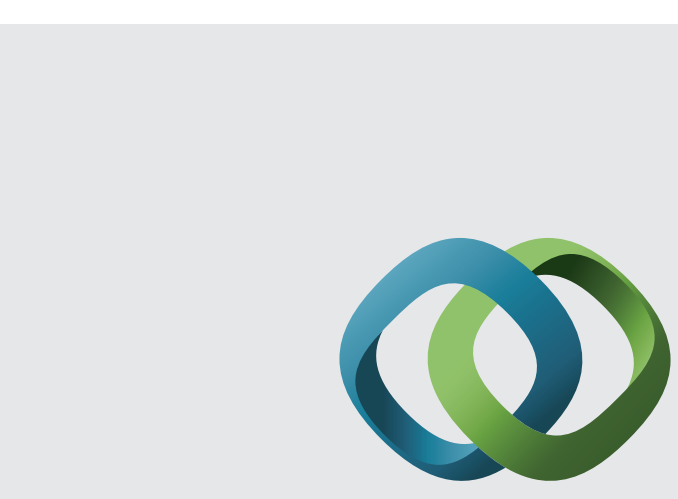

\section{Hindawi}

Submit your manuscripts at

http://www.hindawi.com
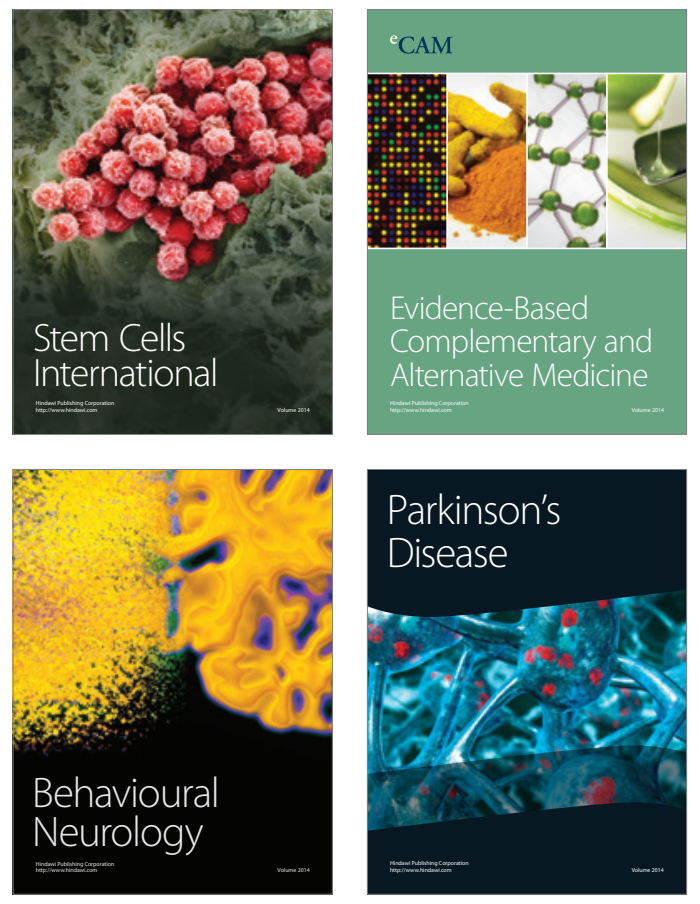
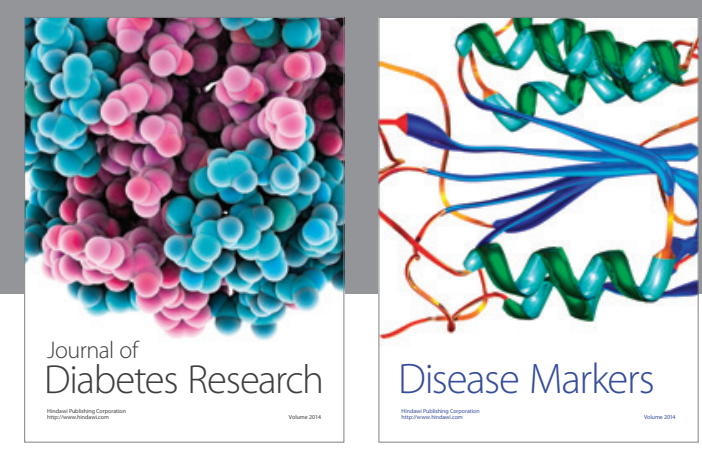

Disease Markers
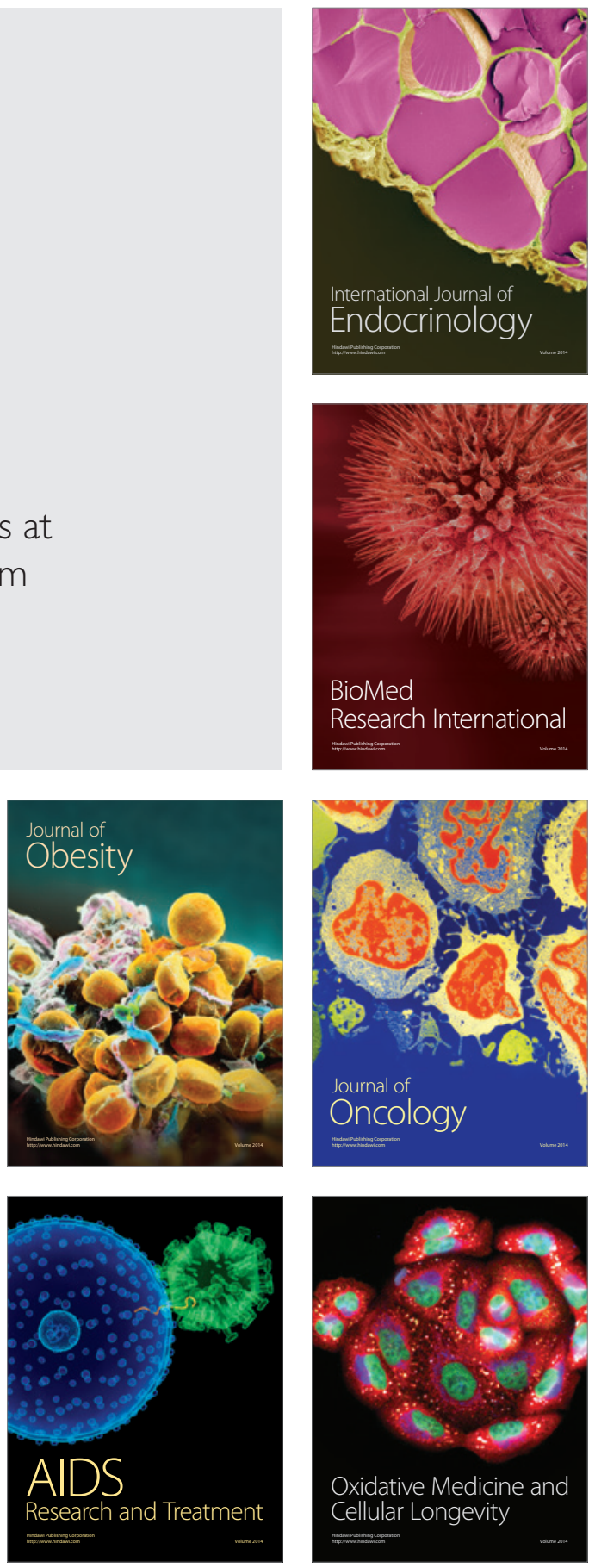